Article

\title{
Development of a Disaster Management Assessment Model Using Resilience Engineering Techniques and Infectious Disease Disaster Management Capacity Assessment
}

\author{
Donghyun Kim ${ }^{1,2, *} \mathbb{D}$, Ji-Hee Lee ${ }^{3}$ \\ 1 Department of Fire Safety Engineering, Jeonju University, Jeonju, Republic of Korea; \\ 72donghyunkim@jj.ac.kr \\ 2 International Institute for Applied Systems Analysis(IIASA), Laxenburg, Austria; \\ 72donghyunkim@gmail.com \\ 3 Daegyeong Regional Infrastructure Technology Development Center, Kyungpook Nat'l University, \\ Kyungpook, Republic of Korea; jihee@knu.ac.kr \\ * Correspondence: 72donghyunkim@jj.ac.kr; Tel.: +82-63-220-2233
}

Version September 30, 2018 submitted to Preprints

\begin{abstract}
Safety management assessment systems for national level units' in South Korea focus on responding capacity to cope with impending accident occurrence and danger occurrence. Since the four stage systems for prevention-preparation-response-recovery, which are core elements of national disaster management, assess the capacities by item such as those of individuals, disaster management departments, institutions, and management networks, there is no assessment function for the organic operation states of the entire systems. Therefore, for efficient disaster management, systematic evaluation indices that will enable active pre-checks in departments in organizations should be developed in place of the existing simply checking methods. In this study, an assessment model that will enable active disaster management centered on practice was developed using resilience engineering techniques. This model consists of disaster management items from the viewpoint of proactive responses instead of prevention. A total of 56 items that constitute four capacities; which are prediction (13 items), monitoring (14 items), proactive response (15 items), and safety learning (14 items) capacities were adopted in this model through Delphi analysis. Institutional capacities for infectious disease disaster management were evaluated based on this model and the resultant scores were prediction 4.41 , monitoring 4.63 , proactive response 4.69 , safety learning 4.56 out of the full score of 5.0 points with an overall average of 4.51 . This is an excellent capacity management score comparable to the score 4.57 of diagnosis of similar capacities by the WHO_JEE (The Joint External Evaluation) in 2017. In fact, in 2015, when infectious disease capacity management was poor, in case of MERS (Middle East Respiratory Syndrome) infectious disease spread in South Korea, 36 patients died and 6,729 patients were isolated. However, through capacity reinforcement, in the case of MERS occurrence in South Korea in September 2018, a management capacity that prevented spread was shown as one confirmed case was completely cured in 10 days and 21 contacts were isolated and tested negative. Therefore, this capacity management assessment model is judged to be usable in enhancing disaster response and management capacities.
\end{abstract}

Keywords: Resilience engineering; Disaster management; Assessment model; Capacity diagnosis; Infectious disease

\section{Introduction}

The patterns of disasters in modern society show the tendency of spread of damage due to unexpected accidental disasters and the lack of crisis management ability even in the case of predictable disasters. Not only in the case of physical disasters such as floods and fires but also in the case of biological disasters such as infectious diseases and livestock epidemics, damage due to predictable or 
unpredictable disasters is gradually increasing and the areas of damage are expanding from local areas to international areas. To respond to such disasters, disaster management and evaluation techniques have been applied by industries and government agencies since the 1930s, and are more actively utilized in modern society [1].

General disaster management systems in South Korean government agencies have been established as four-stage systems consisting of prevention, preparation, response, and recovery stages. However, unlike the original intent to reduce accident occurrences and enhance safety functions, these disaster management systems have been fossilized as established procedures to standardize existing systems to identify and respond to disasters. These existing disaster management systems have limitations in detecting errors or vulnerabilities as they rely on only analyzed data [1].

As disaster management systems become larger and the relationships and cooperation systems among related institutions and stakeholders become more complicated, the relationships between internal and external elements for disaster management should be organically activated. Therefore, in order to secure safety throughout the society, instead of the existing fixed disaster management assessment systems, resilience engineering (hereinafter referred to as "RE") based disaster management assessment techniques that can more clearly resolve problems and improve systems has begun to be utilized in earnest beginning from Europe. Disaster resilience provides a framework for understanding, assessing and managing disaster risk [2,3]. The greatest advantage of this RE is that it does not fix basic RE for organizational capacity assessment and diagnostic tools and apply the tools to systems but provides functions to constantly find holes, errors, new disasters, and problems and revise and supplement them from long-term perspectives [4]. Hong Kong's integrated disaster resilience scored 4.2 out of 5 , indicating a satisfactory performance of the integrated performance of disaster resilience [5].

WHO_JEE is a voluntary, collaborative, multi-sectoral process to assess a country capacity to prevent, detect and rapidly respond to public health risks occurring naturally or due to deliberate or accidental events [6]. The JEE tool - International Health Regulation (IHR, 2005) is intended to assess a country capacity to prevent, detect, and rapidly respond to public health threats independently of whether they are naturally occurring, deliberate, or accidental. The purpose of the JEE process is to measure country specific status and progress in achieving the target [7].

Therefore, this study is intended to analyze existing domestic and abroad disaster management assessment systems and develop a model to assess the disaster management using RE techniques. In addition, models developed for infectious disease disaster management in South Korea were applied and the results were compared and assessed with the results of the WHO_JEE assessment model [8].

\section{Analysis of Disaster Management Assessment System}

\subsection{Domestic disaster management assessment system}

Domestic disaster management assessment systems include national critical infrastructure disaster management assessment, actual disaster management state assessment, and national general safety diagnosis. National critical infrastructures refer to those physical and human systems that can have major effects on human life, properties, and national economy in cases where their functions are paralyzed such as energy, information and communications, traffic and transportation, finance, health and medical service, nuclear power, environment, drinking water, important government facilities and pursuant to article 25-2 of the Framework Act on the Management of Disasters and Safety (hereinafter 'the framework act'), facilities that should be constantly managed for protection of national critical infrastructures are called "national infrastructures" [9]. Pursuant to article 22 of the framework act, the Ministry of Public Administration and Security assessed 118 institutions, 271 facilities in nine areas (energy, information and communications, traffic and transportation, finance, health and medical service, nuclear power, environment, important government facilities, and drinking water) [10]. The national critical infrastructures disaster management assessment consists of four items; response 
capacity, work continuity management, situation management, and score addition/deduction and has been carried out by checking whether the relevant institutions are equipped with basic elements of safety management in relation to the four items.

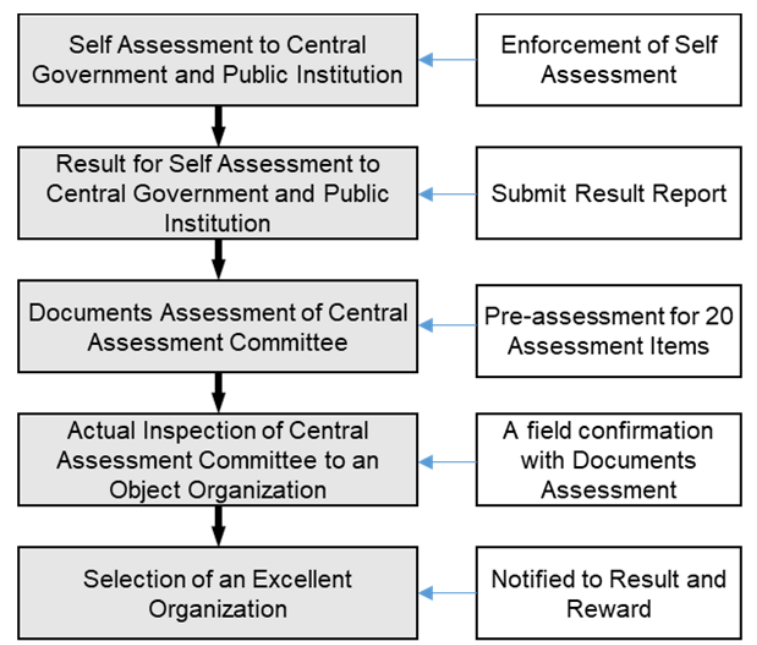

Figure 1. Process of state of disaster management evaluation

The disaster management state evaluation was carried out at the beginning of 2005 to construct advanced national disaster management systems. Pursuant to article 33-3 (public announcement of actual state of disaster management, etc.) of the framework act and article 42-2 of the enforcement ordinance of the same act, in 2017, balance assessments by disaster safety type of 317 institutions (19 central departments, 55 public institutions, 226 cities) centered on common indices were carried out. This disaster management state evaluation consists of five processes and the progression procedure, method, and contents are as shown in Figure 1. The evaluation indices for central departments and public institutions are divided into five categories; personal ability, disaster management department capability, disaster management network capability, agency capacity, and score addition/deduction [11].

Table 1. Comparison of Disaster Management Assessment Model

\begin{tabular}{|c|c|c|}
\hline Assessment Type & Disaster Management Assessment Based National System & Disaster Management Evaluation \\
\hline Indicator & $\begin{array}{l}\text { 1. Response } \\
\text { 2. Business Continuous } \\
\text { 3. Situation Management } \\
\text { 4. Others }\end{array}$ & $\begin{array}{l}\text { 1. Personal Ability } \\
\text { 2. Disaster Management Department Capability } \\
\text { 3. Disaster Management Network Capability } \\
\text { 4. Agency Capability }\end{array}$ \\
\hline How to Proceed & $\begin{array}{l}\text { It is a method to check whether the basic elements of } \\
\text { safety management are provided for nine categories of } \\
\text { national infrastructure by fragmented items. }\end{array}$ & $\begin{array}{l}\text { Whether the basic elements of safety management } \\
\text { are provided for central government agencies, } \\
\text { public agencies, local governments, and written } \\
\text { evaluation and on-site inspection }\end{array}$ \\
\hline
\end{tabular}

The general safety diagnosis has been carried out since 2015 in order to raise the level of national safety and public awareness, to secure social safety, and to promote the development of the safety industry. The responsible bodies are the central government, local autonomous entities, and public institutions and the targets of checks are the facilities subject to legal obligations to check and the implementing bodies according to the laws and systems for the relevant departments.

Table 1 shows a comparison of the index systems and methods of national critical infrastructure disaster management assessments and disaster management failure evaluation. The targets of the national critical infrastructure disaster management assessments are national infrastructures, mainly equipped with index systems for response capacity, work continuity, correlation management, and score addition, etc. The disaster management state evaluation is a little different from the national critical infrastructure disaster management assessments as it evaluates the capacities of individuals, 
management departments, networks, and institutions of the central departments, public institutions, and cities [11].

\subsection{Overseas disaster management assessment system}

After experiencing major disasters such as the 911 terror in 2001, Hurricane Katrina in 2005, and Hurricane Sandy in 2012, the United States developed new policies and related technologies that can be operated efficiently in the field to construct the most advanced systems in the global sector of disaster safety management. After the Hurricane Katrina disaster in 2005, President Obama issued Presidential Policy Directory (PPD) number eight to present a new framework to the Department of Homeland Security in relation to the prevention, protection, mitigation, response, and recovery systems to be prepared for the occurrence of emergency situations. The gist of this directory is to reduce the disaster response authorities originally concentrated on local governments while reinforcing the functions of the federal government, especially the Department of Homeland Security and The Federal Emergency Management Agency so that the central government and the local governments construct an integrated response system [12].

PPD-8 is five national disaster preparation goals consisting of prevention, protection, mitigation, response, and recovery that focused on the reinforcement of organizational capacities to be effectively prepared for and preemptively respond to disasters. The capability-based planning based on these core capacities for national disaster management is not limited to certain disaster situations or scenarios and enables flexible responses even in situations that cannot be easily predicted ( Figure 2) [12].

After the damage by Hurricane Sandy in 2012, the United State recognized the necessity to maintain the functions of urban systems and introduced the concept of resilience in earnest. New York City constructed the New York City Panel on Climate Change (NPCC2) and presented a measure to reinforce resilience through the 'committee for preparation for climate and resilience measure' [13].

In addition, a resilience reinforcement related policies began to be introduced mainly by the US Department of Housing and Urban Development and public participation inviting projects that linked the concept of resilience with recovery and regional development policies were implemented to induce active participation of local residents. Representative resident participatory resilience policies include the design competition titled 'Rebuild by Design' and the '\$1 billion National Disaster Resilience Competition' [14]. In addition, to construct diverse central departments' cooperation systems, the Partnership for Sustainable Communities (PSC), which is a pan-department level partnership, was established in 2009 and diverse departments are currently participating in it including not only the Department of Housing and Urban Development but also the Federal Emergency Management Agency, the Environment Protection Agency, the Department of Transportation, and the Department of Agriculture. In particular, in order to reinforce disaster prevention resilience, the 'Task Force on Climate Preparedness and Resilience' was established in 2013 and the 'Climate Resilience Toolkit' was developed and is supplied to support local governments' and private sector's analysis of resilience. 


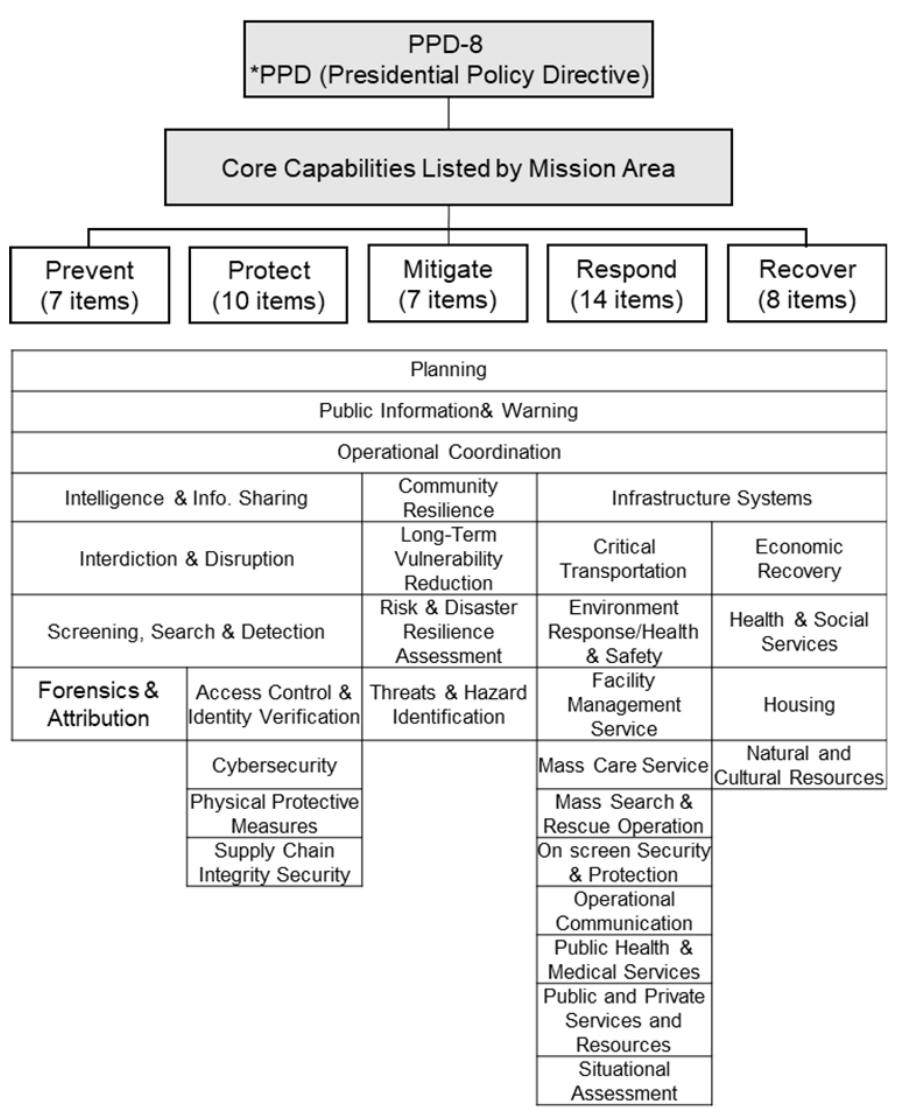

Figure 2. Process of PPD-8 by Federal Emergency Management Agency

\subsection{Resilience engineering analysis}

Past accident analysis and danger management evaluation were based evaluation centered on causal analysis after accident occurrence and the recognition of fundamental problems. This evaluation method has a shortcoming of being unable to find rational causes of failure in the stages ranging from prevention to proactive response stages. On reviewing accident analysis and risk assessment methods by safety paradigm based on times, it can be seen that risk assessment methods have been developed from those based on the mechanical viewpoint of safety against the causes of accidents to those based on human, organizational, and system viewpoints. For instance, mechanical factors related assessment methods include Failure Mode and Effects Analysis (FMEA), Hazard and Operability Analysis (HAZOP), Fault Tree, and FMECA. The assessment methods were developed from accident analysis with the domino theory based on human factors in the 1930s to mechanical defect element analysis in the 1950s, organizational danger management methods in the 1980s, and FRAM and STAMP, which are human and physical system analysis tools, were developed and have been applied since the mid-2000s. New paradigms should be applied to assess the ability of organizational resources to improve the ability to suppress the occurrence of accidents and to ensure safety from a long-term viewpoint. The contents of comparison of traditional paradigms and new paradigms in relation to safety and disasters are as shown in Table 2 [1].

The functions of new paradigms refer to the organizational level ability to suppress accidents and improve safety from a long-term viewpoint. The disaster safety management items include items to evaluate whether functions for actual safety management act instead of the checking method. The viewpoint of existing paradigms is different because it is to evaluate whether facilities, systems, and documents have been prepared and the levels of human and functional performances. The standard assesses relative abilities and pursues progressive securing of insufficient matters. Assessment results 
are fed back to establish long-term improvement plans to pursue improvement at the organizational and institutional levels.

Table 2. Inter-comparison of new change paradigm in disaster management

\begin{tabular}{lll}
\hline Assessment & Traditional Paradigm & New Paradigm \\
\hline Function & $\begin{array}{l}\text { Preparations to reduce human and property } \\
\text { damage in accidents to occur }\end{array}$ & $\begin{array}{l}\text { The ability of organizational resources to } \\
\text { prevent accidents and improve safety capability } \\
\text { from a long-term perspective }\end{array}$ \\
\hline \multirow{2}{*}{ Item } & $\begin{array}{l}\text { Preparatory state for performing specified } \\
\text { safety maintenance function }\end{array}$ & $\begin{array}{l}\text { Ultimately, diagnose whether the function is } \\
\text { working to maintain safety and improve safety } \\
\text { management capability. }\end{array}$ \\
\hline \multirow{2}{*}{ View } & $\begin{array}{l}\text { Assessment of what is based on facilities, } \\
\text { systems, documentation, infrastructure } \\
\text { assessment and hardware }\end{array}$ & $\begin{array}{l}\text { Diagnose what you are doing and what level } \\
\text { you are performing }\end{array}$ \\
\hline \multirow{2}{*}{ Feedback } & $\begin{array}{l}\text { Evaluate whether you meet regulatory } \\
\text { requirements or not. }\end{array}$ & $\begin{array}{l}\text { Relative ability is assessed, and progressive } \\
\text { improvement }\end{array}$ \\
\hline
\end{tabular}

\section{Study Method}

\subsection{Disaster management assessment model based on resilience engineering}

RE-based disaster management assessment construction methods were schematized as shown in Figure 3. A disaster management assessment model derives assessment items through RE application literature in the first stage, selects assessment items after the first Delphi survey, and thereafter conducts the second Delphi survey to collect and analyze the opinions of the expert group in the second stage. In this stage, assessment and index items by core function in each capacity area are derived. In the third stage of disaster management, the interconnectedness, redundancy, and objectivity of the assessment items are secured through the development of an analysis model. In the fourth stage, the third Delphi survey is conducted to derived detailed assessment items through opinion collection, revision, and reflection on the assessment items and selection criteria derived through the second Delphi survey. In the process of progression of the first to third Delphi analysis, detailed assessment items, the contents of assessment, and basic legal systems such as the laws, systems, and self-regulations of disaster related institutions should be checked. Therefore, during the process, information such as the grounds of facts due to the participation of administrative workers of disaster relevant institutions and the present situation of administration should be provided.

\subsection{Delphi analysis}

Delphi analysis is a method to derive collective consensus based on the principle of decision-making as a logical basis when accurate information on the problem to be estimated is necessary. The Delphi method consists of three progression methods: (1) Repetition of procedures and controlled feedback, (2) Anonymity of respondents, and (3) The procedure for statistical group response. In this study, the response panel was organized only with experts and persons in charge in the related fields. 


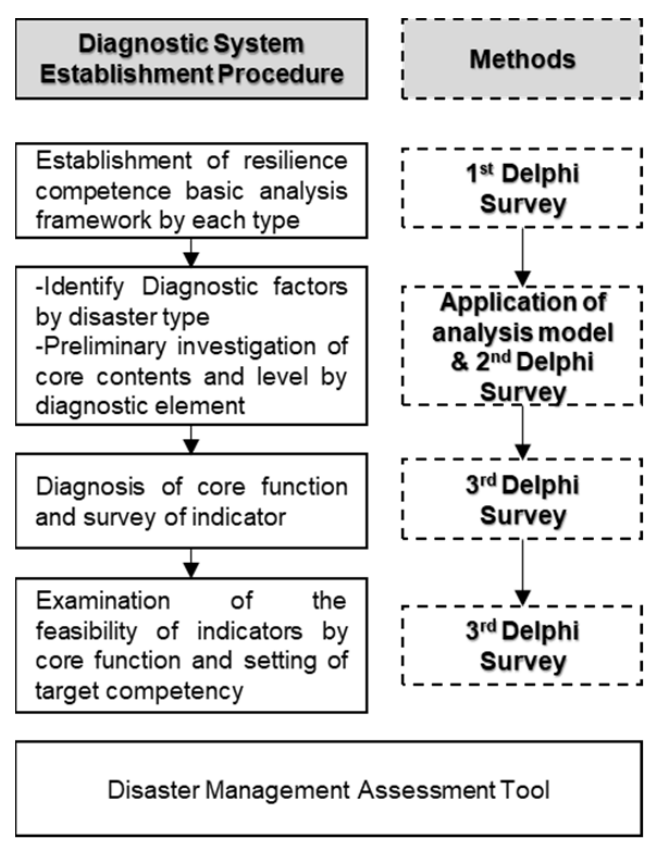

Figure 3. Flowchart of disaster management assessment tool based on resilience engineering

In this study, methods such as self-written opinion collection and re-opinion survey after result editing among the standard Delphi method, which are the most common Delphi processes, were applied. Three Delphi surveys were conducted and in the first survey, panelists' choices and opinions of open-ended questions were collected. In the second survey, some items were deleted and modified through the evaluation of the degree of convergence based on the open-ended questions in the first survey. In the third survey, the final degree of convergence was evaluated for open - ended questions after item deletion and modification. Here, to ensure the homogeneity of the panel, which is respondents, and to prevent deviations of the panel, the respondents were asked to participate in the surveys from the initial opinion collection stage to the re-opinion survey stage. Since Delphi prediction relies on the subjective judgment of the expert panel to estimate the parameter values or propositions, subjective probability methods should be applied. Since Bayesian decision analysis evaluates the probability distribution in the sample space as a process of confidence in uncertain propositions the degrees of convergence were divided into $0-1$ according to the Delphi procedure and those propositions that had the value of the degree of convergence of opinions not smaller than 0.9 (maximum value 1) were regarded to have converged. The expert panelist selection convergence evaluation index $\left(P_{B}\right.$ for open-ended questions is calculated by the following Equation 1 and is determined according to the range of the convergence evaluation index $\left(B_{i}\right)$.

$$
P_{B}=\frac{\sum B_{i}}{P_{n} B_{\text {Max }}} \times 100
$$

where, $B_{i}$ is the convergence evaluation index of individual expert panelists and $\mathrm{P}$ is an expert panelist. In this study, the experts panel was composed of a total of 15 panelists consisting of 6 persons from central departments relates to the field of disasters and 9 external experts. 


\section{Result}

\subsection{Delphi analysis results}

4.1.1. First Delphi analysis

Table 3. Example of Interview Checklist for Diagnosing Disaster Management Assessment

\begin{tabular}{|c|c|c|}
\hline $\begin{array}{l}\text { Diagnostic } \\
\text { elements }\end{array}$ & $\begin{array}{l}\text { Is the level } \\
\text { prediction? }\end{array}$ & of utilization of internal and external knowledge appropriate for future disaster \\
\hline \multirow{3}{*}{$\begin{array}{l}\text { Knowledge } \\
\text { Utilization }\end{array}$} & Optional & $\begin{array}{l}\text { (1) No activity at all } \\
\text { (2) There is no reason(law or regulation) on the utilization of knowledge and } \\
\text { activities, but it is a partial utilization activity by the department and the person } \\
\text { in charge. } \\
\text { (3) It is presented on the minimum task assignment and regularly - it is not regular } \\
\text { but it does not reflect the timely use of knowledge. } \\
\text { (4) There are documented and documented documents related to periodical and } \\
\text { irregular use of knowledge, so there is no immediate reflection stage. } \\
\text { (5) Documents and supporting documents related to non-periodical/periodical } \\
\text { knowledge utilization are provided in laws and regulations, and they are } \\
\text { reflected immediately. }\end{array}$ \\
\hline & Meaning & $\begin{array}{l}\text { It is concerned with the continuing activities of relevant legal systems, } \\
\text { institutions, departments, and personnel involved in the utilization of internal and } \\
\text { external knowledge of the competent ministries. This includes regular and timely } \\
\text { knowledge for changing external circumstances, new forecasting techniques, } \\
\text { Includes activities for utilization. }\end{array}$ \\
\hline & Check list & $\begin{array}{l}\text { - Confirmation of internal and external knowledge utilization activities: } \\
\text { Confirmation of legal, institutional or departmental basis documents. } \\
\text { - Periodic and timely reflection of knowledge utilization confirmation of } \\
\text { preparation and timeliness of the preparation:Diagnosis of interview activities. } \\
\text { * Reflection Timeliness: It refers to a set of prescribed work process activity } \\
\text { levels that are systemized or applied to the field through experts or proven } \\
\text { procedures to improve the field reflection and utilization of new knowledge } \\
\text { both inside and outside the city for more effective pre-disaster prediction. }\end{array}$ \\
\hline
\end{tabular}

In order to select open-ended interview question, an expert panel of 15 disaster related experts was composed and capacity assessment interview items were first extracted. For prediction, monitoring, proactive response, and safety learning areas, up to 22 disaster related interview items per area were presented and a total of 40 items consisting of 73 detailed items; prediction (14 items), monitoring (20 items), proactive response (22 items), and safety learning (17 items) were derived as capacity assessment items. Examples of interview items by the field of open-ended questions are as shown in Table 3. The question items regarding knowledge utilization in the area of prediction consist of the meaning of questions, selection of relevant items, documents and legal regulations, and matters to check for business. In the can of the open-ended interview question items, all expert opinions were collected were reflected on the contents of questions, relevant meanings, matters to be selected, and matters to be checked in the form as shown in Table 3.

\subsubsection{Second Delphi analysis}

The second Delphi analysis was conducted for the 40 items consisting of 73 detailed items in the four areas extracted in the first Delphi analysis. The analysis was conducted on explanatory data considering the intent of the questions and the natures of works that must be checked during disaster management assessments. As a result, among the 73 items, the 62 items were shown to have fitness scores not lower than 0.9 and seven items were shown to have fitness scores lower than 0.9 or shown to be overlapping questions. Therefore, the overlapping question items and items with low fitness scores were reorganized to derive a total of 40 items consisting of 69 detailed items in the four areas 
of prediction (15 items), monitoring (19 items), proactive response (20 items), and safety learning (15 items).

\subsubsection{Third Delphi analysis}

From the 69 detailed items in 40 items in four areas presented in the second Delphi process, 56 detailed items with fitness scores not lower than 0.9 were selected through a survey of the degree of convergence of opinions of the same experts. The individual diagnostic items were adopted after revising the fitness scores based on the diagnosis assessment scale criteria to be at least 0.9. Finally, a total 56 items in the areas of prediction (13 items), monitoring (14 items), proactive response (15 items), and safety learning (14 items) were derived as capacity assessment items. The changes in detailed assessment items in the $1^{\text {st }}, 2^{\text {nd }}$, and $3^{\text {rd }}$ Delphi analysis processes reflecting the degrees of convergence of opinions are as shown in Table 4.

Table 4. Changes in Diagnostic Items through Delphi Analysis Process

\begin{tabular}{lcc}
\hline & $\begin{array}{c}1^{\text {st }} \text { Delphi } \\
\text { (73 items) }\end{array}$ & $\begin{array}{c}2^{\text {nd }} \text { Delphi } \\
\text { (69 } \text { items) }\end{array}$ \\
\hline Prediction & 14 & 15 \\
Monitoring & 20 & 19 \\
Respond & 22 & 20 \\
Learning & 17 & 15 \\
\hline
\end{tabular}

\subsection{Capacity diagnosis item}

\subsubsection{Prediction}

Prediction capacities refer to those proactive response capacities to minimize the risk of accident occurrence and resultant damage through short/long-term prediction by assessment of internal/external environmental factors, the composition of resources, and institutional support in relation to system safety and social danger elements. Prediction capacity diagnostic elements were composed of (1) Expertise, (2) Prediction frequency, (3) Information sharing, (4) Prediction model, (5) Prediction time, (6) Prediction reliability, (7) Decision making, (8) Organizational consciousness, (9) Prediction resource, and (10) Resource efficiency.

\subsubsection{Monitoring}

Monitoring can be defined as the ability to identify external environment factor variables and internal safety maintenance states and immediately recognize impending disasters or the possibility of accident occurrence. This includes the sensing, checking, and recovery functions to sense disaster occurrence and resultant risks of damage in order to maintain safe states. Monitoring diagnostic elements were composed of (1) Index list, (2) Fitness, (3)Index type, (4) Preceding assessment validity, (5) Time delay, (6) Measurement type, (7) Analysis frequency, (8) Analysis suitability, (9) Effectiveness, and (10) Organization support.

\subsubsection{Proactive response}

Proactive responses can be defined as the ability of the internal or external linked response unit organizations to conduct responding activities with organized systems to reduce disaster accidents and resultant damage until the stage before the expansion of the disaster into a large disaster. In a broad sense, proactive responses includes the ability to conduct a series of response activities to maintain or restore safe or steady states in the stage after disaster occurrence before expansion. RE perspective proactive responses are to secure functions such as policies, organizations, and resource capacities with the goal of preventing accident occurrence per se without focusing on the field response ability after an accident occurrence. The proactive response diagnostic elements were composed of (1) Accident item, 
(2) Selection basis, (3) Amendment appropriateness, (4) Initiation standard, (5) Behavior standard, (6) Promptness, (7) Duration, (8) Resource mobilization, (9) Termination criteria, and (10) Waiting criteria.

\subsubsection{Safety learning}

Safety learning is the ability to enhance the safety learning capacity for personal experience and knowledge, as well as the ability to expand and utilize individuals' expertise in the entire organization thereby systematically accumulate the expertise into knowledge. The safety learning diagnostic elements were composed of (1) Selection criteria, (2) Learning standards, (3) Learning materials, (4) Classification methods, (5) Learning frequency, (6) Learning resources, (7) Rapid learning, (8) Learning objectives, (9) Learning execution, and (10) Verification / operation.

\subsection{Infectious disease disaster management capacity assessment}

In South Korea, infectious disease disaster management is a major task of the Korea Centers for Disease Control and Prevention of the Ministry of Health and Welfare. Therefore, using the disaster management capacity diagnosis model developed in this study, an internal and external expert group was composed to conduct field surveys and interviews on the infectious disease disaster management documents of the Korea Centers for Disease Control and Prevention, laws and regulations, activities, systems, and learning methods. According to the diagnosis of infectious disease disaster management capacities, as shown in Table 5, the overall average of the internal and external experts was high as 4.51, and among the detailed capacities, proactive responses showed the highest score 4.69 followed by safety learning 4.56, prediction 4.41, and monitoring 4.36. The deviation rate between the assessment by external experts and self-assessment was 7.79\%. Self-assessment scores were about $10.14 \%$ higher on prediction and monitoring while external experts' assessment scores were about $5.83 \%$ higher on proactive responses and safety learning.

Table 5. Infectious disease management capacity diagnosis results (+ means that the results of self-assessment are higher and - means that the results of external assessment are higher)

\begin{tabular}{lcccc}
\hline & Self assessment & $\begin{array}{c}\text { External experts } \\
\text { assessment }\end{array}$ & Mean & $\begin{array}{c}\text { Deviation rate } \\
{[\%]}\end{array}$ \\
\hline Prediction & 4.75 & 4.07 & 4.41 & +11.30 \\
Monitoring & 4.63 & 4.09 & 4.36 & +8.98 \\
Respond & 4.55 & 4.83 & 4.69 & -4.72 \\
Learning & 4.35 & 4.77 & 4.56 & -6.94 \\
\hline
\end{tabular}

As shown in Figure 4, in the results of RAG (Resilience Analysis Grid) diagnostic analysis of detailed items of prediction capacities, the score of information sharing (5.00) was the highest followed by expertise (4.83), prediction time (4.67), decision making (4.67), prediction model (4.61), prediction frequency (4.50), organizational consciousness (4.50), resource efficiency monitoring capacities (4.00), prediction reliability (3.67), and prediction resource (3.67). In the results of diagnostic analysis of detailed items of monitoring capacities, the score of time delay (4.84) was the highest followed by analysis frequency (4.84), index list (4.67), index type (4.67), measurement type (4.59), fitness (4.50), analysis suitability (4.50), organization support (4.17), preceding assessment validity (3.50), and effectiveness (3.34). In the results of diagnostic analysis of detailed items of proactive responding capacities, the score of amendment appropriateness (5.00) was the highest followed by initiation standard (4.92), duration (4.92), accident item (4.84), resource mobilization (4.84), waiting criteria (4.59), behavior standard (4.50), termination criteria (4.50), selection basis (4.50), and promptness (4.33). In the results of diagnostic analysis of detailed items of safety learning capacities, the score of learning standards (4.67) was the highest followed by learning materials (4.83), learning resources (4.83), learning objectives (4.83), verification / operation (4.75), selection criteria (4.50), learning frequency (4.50), rapid learning (4.33), learning execution (4.33), and classification methods (4.00). 

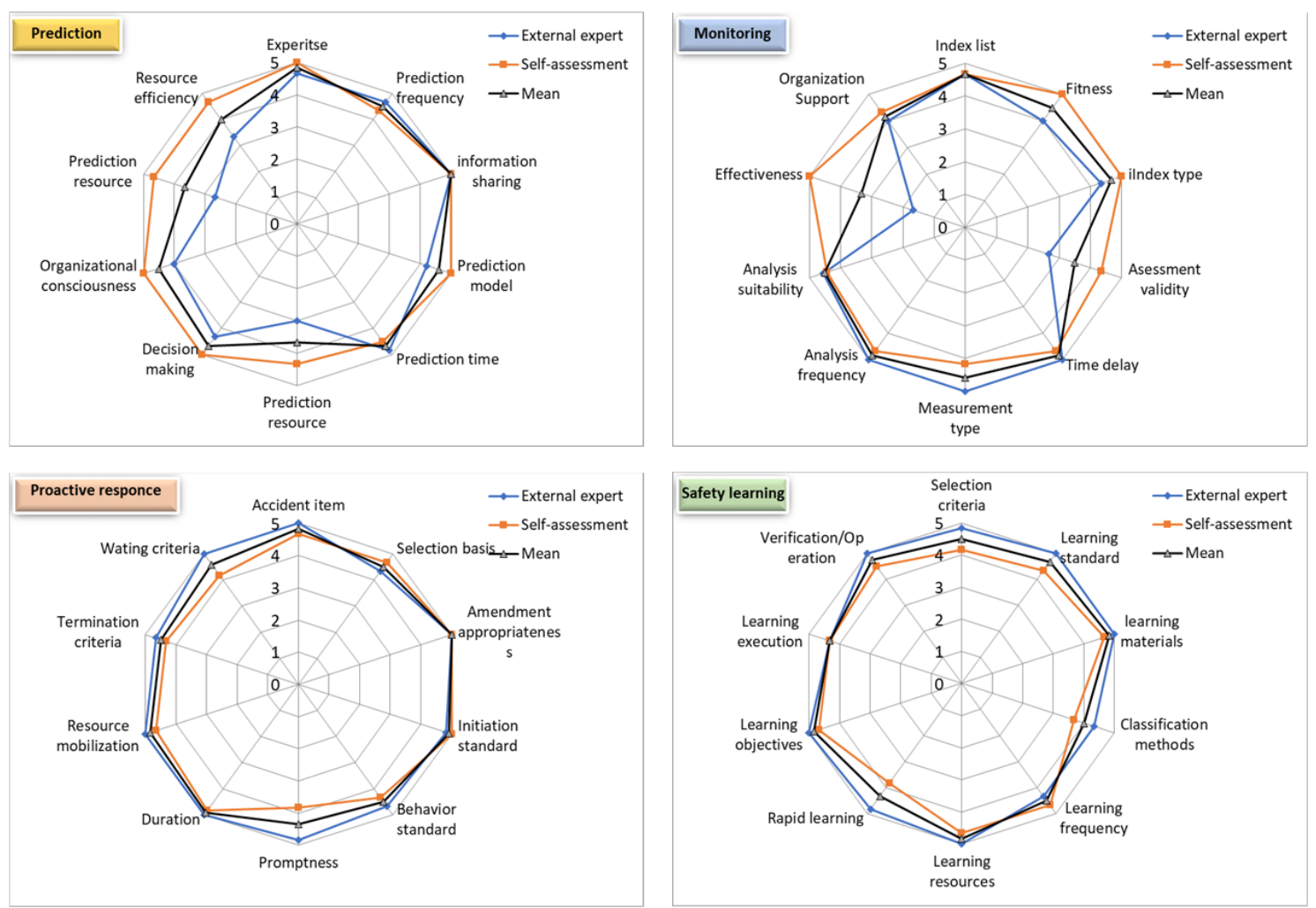

Figure 4. Results on detailed RAG diagnosis of infectious disease management capacity (Results of RAG diagnosis of each of prediction, monitoring, proactive response, and safety learning capacity)

\section{Discussion}

In order to secure the reliability of the capacity diagnosis assessment model proposed in this study, the results of assessment of the proposed model were compared with the results on assessment of JEE, which is an infectious disease management capacity diagnostic program of the WHO. The JEE share a number of important features, including: voluntary country participation; a multi-sectoral approach by both the external teams and the host countries; transparency and openness of data and information sharing; and the public release of reports. It also refers to the joint process during an external evaluation (envisioned to take place approximately every five years) where a team of national experts first prepares a self-assessment supplied to the external team prior to the on-site visit, and the external team uses the same tool for their independent evaluation, working together with the national team in interactive sessions [6]. WHO_JEE consists of 48 detailed items in 4 main areas, which are prevention, sensing, response, and others [7]. From 28 August to 1 September 2017, the JEE mission took place in the Rep. of Korea, where a multi-sectoral team of international and national expert jointly conducted a review of Rep. of Korea's IHR core capacities in the 19 technical areas and 48 detailed items using the JEE tool [8]. The number and contents of detailed items do not agree with the 56 items of four major capacities proposed in this study when compared with each other. However, the meanings of the detailed assessment items were analyzed and compared with the four major capacity items of the model in this study. As a result, as shown in Table 6, the deviation by capacity were shown to be prediction capacity 0.26 , monitoring 0.41 , proactive response 0.69 , and safety learning 0.17 , and the deviation of the overall average was shown to be 0.06. In fact, in the case of the MERS infectious disease spreading occurred in South Korea in 2015, 36 patients died and 6,729 patients were isolated. The Korea Centers for Disease Control and Prevention has reinforced capacities such as improvement of manpower, systems, laws and systems, and preparation of learning capacity, equipment, and wards since 2015. As a result, in the present capacity management diagnosis, a score of 4.51 was given and in WHO_JEE diagnosis, a score of 4.57 was given, indicating that the management capacity is sustainable. 
Thereafter, in the case of MERS occurrence in South Korea in September 2018, one confirmed case was recovered in 10 days and 21 contacts were isolated and judged negative indicating that the infectious disease did not spread. Therefore, this capacity management assessment model is judged to become a tool to improve and continuously maintain and manage disaster response and management capacities. However, in conclusion of WHO_JEE 2017 South Korea result, South Korea demonstrated a high level of capacity as 4.57 out of 5 in this JEE. It is important to note that having sustainable capacity across many technical areas also means there is an obligation to proactively support the other Member States in the region to maintain and strengthen their core capacities [8].

Table 6. Comparison between the mean values of the results of infectious disease management capacity diagnosis between proposed REG and WHO_JEE capacity diagnosis

\begin{tabular}{ccc}
\hline & $\begin{array}{c}\text { Proposed diagnosis results } \\
\text { (Max. 5) }\end{array}$ & $\begin{array}{c}\text { WHO_JEE South Korea results } \\
\text { (Max. 5) }\end{array}$ \\
\hline Prediction & 4.41 & 4.67 \\
Monitoring & 4.36 & 4.77 \\
Respond & 4.69 & 4.00 \\
Learning & 4.56 & 4.83 \\
\hline The mean of results & 4.51 & 4.57 \\
\hline
\end{tabular}

\section{Conclusion}

For the assessment of organizations' ability to suppress accidents and enhance safety from a long-term viewpoint in place of the paradigm to be prepared against human life and property losses in impending accidents in a short-term viewpoint for efficient disaster management in the case of the occurrence of diverse disasters, practice centered disaster management assessment items are necessary. Therefore, in this study, a disaster management assessment model based on practice centered active new paradigms was presented and infectious disease disaster area capacity management assessments were conducted. As a result, the following conclusions were obtained.

- A disaster management assessment model for four stages; prediction, monitoring, proactive response, and safety learning was presented

- A disaster management assessment item selection method using the Delphi analysis technique that includes expert panel composition and opinion convergence processes was presented.

- Finally, assessment criteria for a total of 56 detailed items in four stages, which are prediction (13 items), monitoring (14 items), proactive response (15 items), and safety learning (14 items), were presented.

- Infectious disease management capacity assessment was conducted and the results indicated that the capacity management was excellent with an overall average score of 4.51, which is similar to the score 4.57 of WHO_JEE sustainable disaster capacity management assessment with an deviation value of 0.06 .

As can be seen from the results of 2015 and 2018 MERS infectious disease spread actually occurred in South Korea, the present capacity diagnosis assessment model is judged to be helpful for more objective capacity diagnosis and sustainable capacity management [8]. Based on the disaster management assessment items presented through the results of this study, institution capacity diagnoses by disaster will be conducted hereafter so the vulnerable areas and problems can be improved and supplemented.

\section{References}

1. Hollnagel, E. Safety-I and Safety-II, The Past and Future of Safety Management. ASHGATE, 2014.

2. Manyena, S.B. The concept of resilience revisited. Disasters, 2006, 30(4), 434-450.

3. Kapucu, N.; Hawkins, C.V.; Rivera, F.I. (Eds.) Disaster Resiliency: Interdisciplinary Perspectives, 1st ed.; Kapucu, N. Hawkins, C.V. Rivera, F.I.; Routledge: New York, NY, USA, 2014; 978-1-138-83326-5, ISBN. 
4. Hollnagel, E. Resilience engineering: concepts and precepts; Woods, D.D., Leveson, N., Hollnagel, E. ASHGATE, 2012

5. Sim T., Wang D., and Han Z. Assessing the Disaster Resilience of megacities, The Case of Hong Kong, Substantiality 2018, 10, 1137, doi:10.3390

6. WHO, Joint External Evaluation(JEE) mission reports. Available online: http://www.who.int/ihr/ procedures/mission-reports/en/ (accessed on 3 September 2018).

7. WHO, Joint External Evaluation(JEE) Tool, International Health Regulation (IHR) Monitoring and Evaluation Framework, ISBN 978924151017 2, 2005, 101.

8. WHO, Joint External Evaluation(JEE) of International Health Regulation (IHR) Core Capacities of the Republic of Korea, Mission Report, 2017 WHO/WHE/CPI/2017.65, . 84. http:/ / www.who.int/ihr/publications/jee-mission-report-rok/en/ (accessed on 3 September 2018)

9. Republic of Korea's Ministry of Public Safety and Security, Report of Disaster Management Assessment based on National System, 2012.

10. Republic of Korea's Ministry of Public Safety and Security, Special Disaster Management Office, Report of Assessment for Disaster Management based on Nation, 2016.

11. Ministry of Public Safety and Security, Result Report of Special Disaster Management Ability for Pilot Diagnosis, 2016.

12. FEMA, Presidential Policy Directive-8 National Preparedness.2013, https:/ / www.fema.gov/learn-about-presidential-policy-directive-8 (accessed on 3 September 2018).

13. The White House, The President's Climate Action Plan, Executive of the President, 2013.

14. Han, W.S. The concept of Resilience in Disaster prevention and Application in U.S.A, The Magazine of Korean Society of Hazard Mitigation, 2017, 40-43.

Sample Availability: Samples of the compounds ...... are available from the authors. 